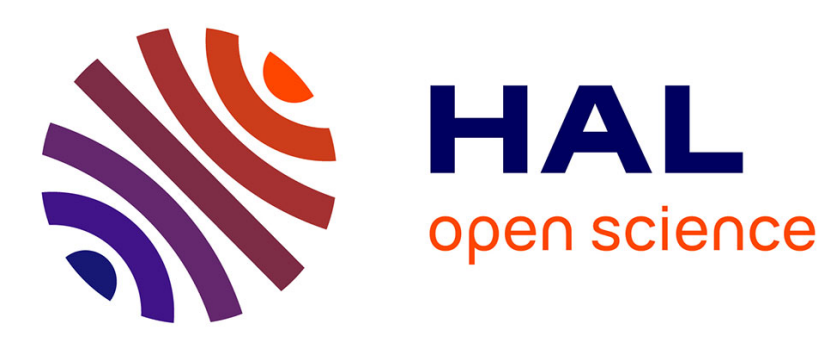

\title{
Design and Control of a Novel 4-DOFs Parallel Robot H4
}

Hee-Byoung Choi, Olivier Company, François Pierrot, Atsushi Konno, Tetsuro Shibukawa, Masaru Uchiyama

\section{- To cite this version:}

Hee-Byoung Choi, Olivier Company, François Pierrot, Atsushi Konno, Tetsuro Shibukawa, et al.. Design and Control of a Novel 4-DOFs Parallel Robot H4. ICRA: International Conference on Robotics and Automation, Sep 2003, Taipei, Japan. pp.1185-1190, 10.1109/ROBOT.2003.1241753 . lirmm00269434

\section{HAL Id: lirmm-00269434 https://hal-lirmm.ccsd.cnrs.fr/lirmm-00269434}

Submitted on 3 Apr 2008

HAL is a multi-disciplinary open access archive for the deposit and dissemination of scientific research documents, whether they are published or not. The documents may come from teaching and research institutions in France or abroad, or from public or private research centers.
L'archive ouverte pluridisciplinaire $\mathbf{H A L}$, est destinée au dépôt et à la diffusion de documents scientifiques de niveau recherche, publiés ou non, émanant des établissements d'enseignement et de recherche français ou étrangers, des laboratoires publics ou privés. 


\title{
Design and Control of a Novel 4-DOFs Parallel Robot H4
}

\author{
H.B. Choi*, O. Company**, F. Pierrot**, A. Konno*, T. Shibukawa**, and M. Uchiyama* \\ ${ }^{*}$ Department of Aeronautics and Space Engineering, Tohoku University \\ Aoba-yama 01, Sendai 980-8579, Japan \\ **LIRMM, 161, Rue Ada, 34392 Montpellier Cedex 5, France \\ ***Technical R \& D Center, Toyoda Machine Works, Ltd. \\ Asahimachi 1-1, Kariya, Aichi 448-8652, Japan. \\ e-mail:\{ojhee, konno, uchiyama\}@space.mech.tohoku.ac.jp \\ \{company, pierrot\}@lirmm.fr \\ shibukawa@fsh.toyoda-kouki.co.jp
}

\begin{abstract}
This paper deals with the design and dynamic control simulation of a new type of 4-DOFs parallel mechanism providing 3 translations and 1 rotation for highspeed handling and machining. This parallel mechanism is named as H4. A model-based dynamic control scheme is developed to improve the accuracy of the trajectory tracking. A simplified dynamic model is used for the $\mathrm{H}_{4}$ robot to decrease the cost of computation. A dynamic simulation is performed using $\mathrm{ADAMS}^{\mathrm{TM}}$. In addition, the Adept motion is used as a benchmark test to evaluate the effect of the dynamic control. The simulation results show that the dynamic control dramatically improves the trajectory tracking accuracy.
\end{abstract}

\section{Introduction}

Recently, parallel robots have been studied enthusiastically because their capabilities are superior to those of conventional serial robot in many aspects [1] [14]. The notable characteristics of the parallel mechanism are high accuracy, high load capacity, high rigidity, and quickness. The concept of using the parallel mechanism as a spacial motion mechanism with 6 -DOFs dates back to the paper by Gough [1]. Stewart proposed a 6 -DOFs platform targeting its application to a flight simulator [2]. Minsky proposed that the parallel mechanism should be used as the motion mechanism of manipulators [3]. Then, the use of industrial robots spread in the 1980s, and active studies of robots were conducted. As a result, people paid attention to the parallel mechanisms as the novel motion mechanisms of robots, and several researchers specifically pointed out their advantages [4]-[6].

In the period from 1980s to present, many theoreti- cal studies have been conducted, and new mechanisms have been proposed. Clavel proposed a high-speed parallel robot DELTA equipped with spatial 3-DOFs [7]. It is used in industry for high speed handling applications but its application is limited because its degrees of freedom are too small to perform a complicated task. In some case, a DELTA robot can have 6DOFs in total adding a serial-actuated 3-DOFs. This kind of serial-parallel hybrid robot is not as efficient as a fully-parallel robot. In contrast, Pierrot proposed a 6-DOFs fully-parallel robot HEXA [9][10] which is the expansion of the DELTA mechanism. However, HEXA robot suffer from its high-price, small tilting angle, and complexity.

There are a lot of applications in which 3-DOFs are not enough and 6-DOFs are too much. For example, 4-DOFs (3-DOFs for translation and 1-DOF for rotation) are necessary and enough for pick-andplace tasks. Nevertheless, only few attempts have so far been made at 4-DOFs parallel robots. Pierrot proposed 4-DOFs parallel mechanisms called H4 [12]-[14] against such a background.

In this paper, we discuss a new 4-DOFs parallel mechanism. The mechanism realizes a wide workspace as well as high-speed. Since the name of H4 is generically used not for one mechanism but for some types of mechanism [12], we name this new mechanism $\mathrm{H} 4$, too. A dynamic simulation was done using $\mathrm{ADAMS}^{\mathrm{TM}}$. In order to improve trajectory-tracking accuracy of the $\mathrm{H} 4$ robot, a dynamic control scheme is developed, and a simplified dynamic model of $\mathrm{H} 4$ structure which was proposed by Pierrot [12] is used for the control. The Adept motion was chosen as a benchmark test to evaluate its capability of fast motion. The results of the benchmark test are presented. 


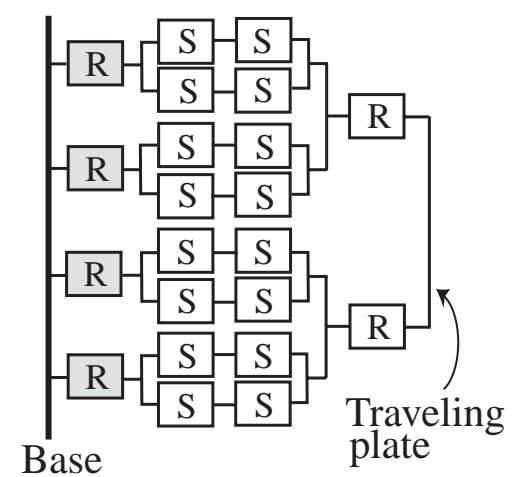

(a) Architectural scheme

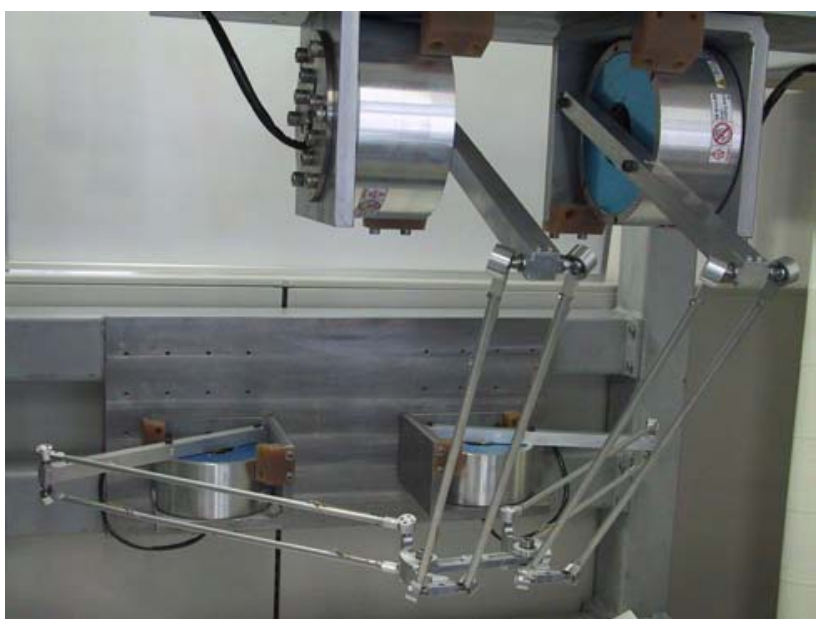

(b) The prototype of $\mathrm{H} 4$

Figure 1: Kinematic structure of H4

\section{A 4-DOFs parallel robot $\mathrm{H} 4$}

The basic concept of $\mathrm{H} 4$ is described by a simple architectural scheme illustrated in Figure 1 (a), where joints are represented by rectangles and links between those joints are represented by lines. Let $\mathrm{P}, \mathrm{R}, \mathrm{U}$ and $\mathrm{S}$ represent prismatic, revolute, universal and spherical joint, respectively. A quasi-equivalence exists between $U-U$ and $(S-S)_{2}$ chains [12] so that $(S-S)_{2}$ chain is chosen for the prototype of H4. Figure 1 (b) shows the prototype of $\mathrm{H} 4$.

\subsection{Motors}

The robot employs M-SSB014, NSK, which are directdriven type motors embodying encoders. The maximum torque, rated speed and weight are 14 [Nm], 3.75 [rps] and $6[\mathrm{~kg}]$, respectively.

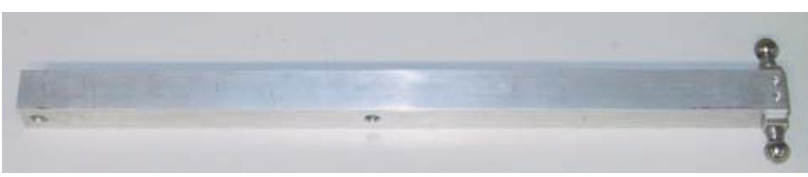

Figure 2: Arms

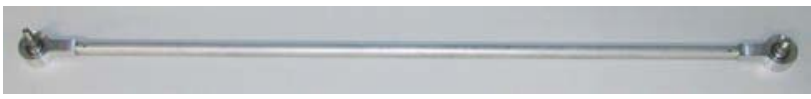

Figure 3: Rods

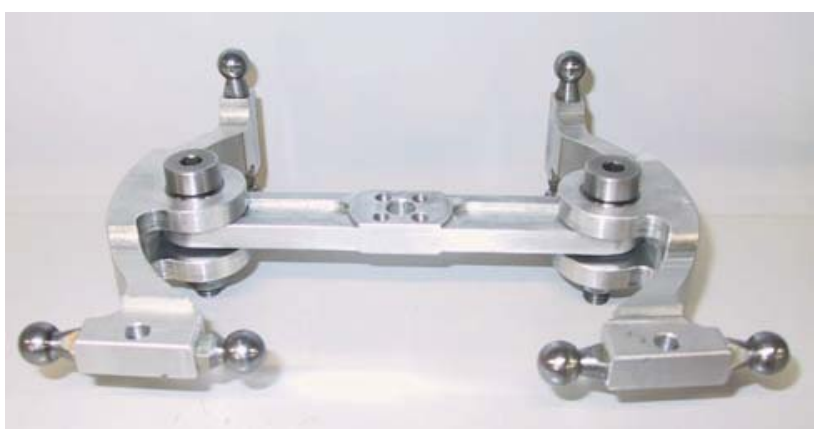

Figure 4: Traveling plate
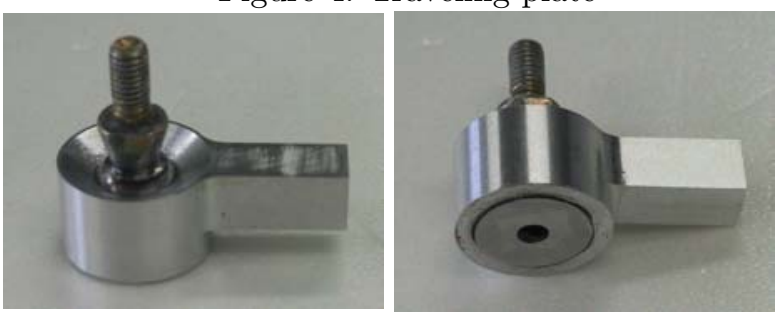

Figure 5: ball joint

\section{$2.2 \quad$ Arms}

The arms consist of $0.26[\mathrm{~m}]$ long, square hollow pipes made of $2[\mathrm{~mm}]$ thick aluminum plate so that their weight is as light as possible (Figure 2). The crosssection is a $20[\mathrm{~mm}] \times 20[\mathrm{~mm}]$ square. The moment of inertia around the rotary axis is $2.34 \times 10^{-3}\left[\mathrm{kgm}^{3}\right]$. Each arm has an operating range of $130\left[^{\circ}\right]$, which is limited by mechanical stoppers made of synthetic resin.

\subsection{Rods}

The rod consists of a $0.48[\mathrm{~m}]$ long aluminum pipe whose outside diameter is 8 [mm] and wall-thickness is 1 [mm], making it as light as possible (Figure 3). The calculated mass of the rod itself, the outer rings of the two joints, and the rod as a whole are 28 [g], 20 [g], and 48 [g], respectively. 


\subsection{Travelling plate}

The travelling plate are composed of two lateral bars and one central bar. The possible motions of two lateral bars and one central bar are translation, and translation-rotation, respectively. The travelling plate is made of aluminum plate making it as light as possible. Its observed mass is $0.5[\mathrm{~kg}]$. The center of central bar is machined so that an end-effector can be mounted. Figure 4 represent the travelling plate of the H4 prototype. Geometric description of the travelling plate is illustrated in Figure 6

\subsection{Ball joints}

The arms and the rods, and the rods and the travelling plate are joined with ball joints. Figure 5 illustrates the ball joint. The ball joints obtained on the market were reprocessed so that the movable ranges were increased to $40\left[^{\circ}\right]$ in order to expand the movable range of the $\mathrm{H} 4$ robot. Especially, the ball joint proposed by Kim [15] is made using epoxy bond without any special techniques so that it is realized a comparatively cheaper ball joint with a large swing angle.

\section{Kinematics of the $\mathrm{H} 4$}

\subsection{Geometric description}

The parameters $L, M, A$ and $h$ are the length of the arm, the rod, the offset of the motor axis from the center of the base, and the offset of each ball-joint from the center of traveling plate, respectively. The points $A_{i}, B_{i}$ and $C_{i}$ in Figure 6 are the center of the respective joints. The number $i=1,2,3,4$ represents each pair of kinematic chains. Let us define frames:

- $\Sigma_{\mathrm{b}}$ : a reference frame fixed on the base.

- $\Sigma_{\mathrm{t}}$ : a frame fixed on the traveling plate.

- $\Sigma_{\mathrm{a} i}$ : a reference frame fixed on the root of the $i$ th chain and defined with $\boldsymbol{y}_{a i}=\boldsymbol{z}_{b}(i=1,2)$, $\boldsymbol{z}_{a i}=\boldsymbol{z}_{b}(i=3,4)$ and $\boldsymbol{y}_{a i}$ parallel to the first joint axis of the $i$ th $\operatorname{chain}(i=1,2,3,4)$

The parameters $L, M, h, Q_{y}$, and $Q_{z}$ used in this simulation are, $0.26[\mathrm{~m}], 0.48[\mathrm{~m}], 0.06[\mathrm{~m}]$ and 0.42 $[\mathrm{m}]$, respectively.

\subsection{Inverse kinematics}

As it is usual for most parallel robots, the inverse kinematics of $\mathrm{H} 4$ is easily derived. The traveling plate are composed of 3 parts (2 lateral bar and 1 central

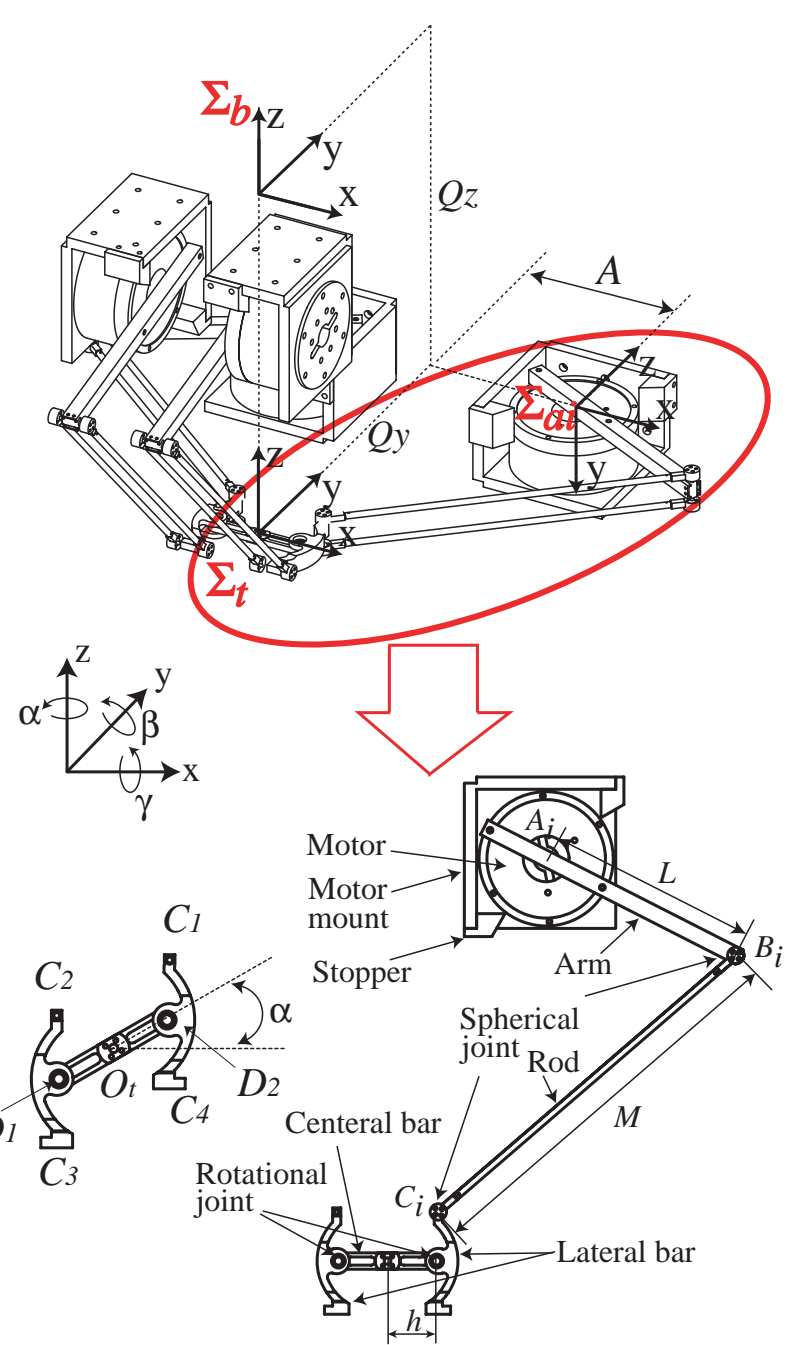

Figure 6: Design parameters

bar, see Figure 6 ). The four points $C_{1}, C_{2}, C_{3}$, and $C_{4}$ forms a parallelogram.

Let ${ }^{t} \boldsymbol{C}_{i},{ }^{a i} \boldsymbol{B}_{i}$ and ${ }^{a i} \boldsymbol{C}_{i}$ represent the homogeneous coordinates of the points $\boldsymbol{C}_{i}$ in $\Sigma_{t}, \boldsymbol{B}_{i}$ in $\Sigma_{a i}$ and $\boldsymbol{C}_{i}$ in $\Sigma_{a i}$, respectively. Then the coordinates of ${ }^{t} \boldsymbol{C}_{i}$ can be written as:

$$
{ }^{b} \boldsymbol{C}_{i}=\left[\begin{array}{c}
x+h E_{1 i} \cos \alpha \\
y+h E_{1 i} \sin \alpha+h E_{2 i} \\
z \\
1
\end{array}\right]
$$

where, $(x, y, z)$ is the position of $O_{t}$ in $\Sigma_{b}$ and

$$
\begin{array}{ll}
E_{11}=E_{14}=1, & E_{12}=E_{13}=-1, \\
E_{21}=E_{22}=1, & E_{23}=E_{24}=-1 .
\end{array}
$$


The coordinates of ${ }^{a i} \boldsymbol{B}_{i}$ and ${ }^{a i} \boldsymbol{C}_{i}$ can be derived as:

$$
{ }^{a i} \boldsymbol{B}_{i}=\left[\begin{array}{c}
L \cos \theta_{i} \\
0 \\
-L \sin \theta_{i} \\
1
\end{array}\right], \quad{ }^{a i} \boldsymbol{C}_{i}={ }^{a i} \boldsymbol{T}_{b}{ }^{b} \boldsymbol{C}_{i}=\left[\begin{array}{c}
{ }^{a i} \lambda_{i} \\
{ }^{a i} \rho_{i} \\
{ }^{a i} \mu_{i} \\
1
\end{array}\right]
$$

where, ${ }^{a i} \boldsymbol{T}_{b}$ and ${ }^{b} \boldsymbol{T}_{t}$ represent the homogeneous transfer matrices from $\Sigma_{b}$ to $\Sigma_{a i}$ and $\Sigma_{t}$ to $\Sigma_{b}$, respectively.

The kinematic closure of each elementary chain can be written as:

$$
\left\|\overrightarrow{B_{i} C_{i}}\right\|^{2}=M^{2}
$$

Solving Equation (1), the motor angles $\theta_{i}$ are given by:

$$
\theta_{i}=2 \tan ^{-1}\left(\frac{-{ }^{a i} \mu_{i} \pm \sqrt{{ }^{a i} \mu_{i}^{2}+{ }^{a i} \lambda_{i}^{2}-W_{i}^{2}}}{{ }^{a i} \lambda_{i}+W_{i}}\right)
$$

where

$$
W_{i}=\frac{L^{2}-M^{2}+{ }^{a i} \mu_{i}^{2}+{ }^{a i} \lambda_{i}^{2}+{ }^{a i} \rho_{i}^{2}}{2 L} .
$$

\subsection{Forward kinematics}

In general, it is easy to solve the inverse kinematics of a parallel robots analytically. On the other hand, it is generally difficult to solve the forward kinematics of a parallel robot analytically. The forward kinematics of the $\mathrm{H} 4$ is the problem of computing the position and orientation of the traveling plate from the motor angles. To get a closed-form solution, we need to solve a set of four nonlinear simultaneous equations. Closedform solution for the forward kinematics has not been found yet. Therefore, we employ the Newton-Raphson method to solve it, numerically [8].

\section{Dynamics of the $\mathrm{H} 4$}

A simplified dynamic model [9] is used to describe the dynamics of H4. The simple model supposes that a half of the rod mass is added to the arm and another half is added to the traveling plate and that the rod itself is massless and inertia-less. This assumption greatly contributes to reduce the cost of dynamics calculation. $D_{1}$ and $D_{2}$ are the points corresponding to the two rotation joints on the traveling plate. Let ${ }^{b} \dot{\boldsymbol{p}}_{O_{t}},{ }^{b} \dot{\boldsymbol{p}}_{D_{1}}$ and ${ }^{b} \dot{\boldsymbol{p}}_{D_{2}}$ represent the velocity vectors of point $O_{t}, D_{1}$ and $D_{2}$ in $\Sigma_{b}$, respectively. The relationship leads to:

$$
{ }^{b} \dot{\boldsymbol{p}}_{D_{1}}=\boldsymbol{T}_{1}{ }^{b} \dot{\boldsymbol{p}}_{O_{t}}=\boldsymbol{T}_{1} \boldsymbol{J} \dot{\boldsymbol{\theta}}, \quad{ }^{b} \dot{\boldsymbol{p}}_{D_{2}}=\boldsymbol{T}_{2}{ }^{b} \dot{\boldsymbol{p}}_{O_{t}}=\boldsymbol{T}_{2} \boldsymbol{J} \dot{\boldsymbol{\theta}}
$$

where,

$$
\begin{aligned}
& \boldsymbol{T}_{1}= {\left[\begin{array}{cccc}
1 & 0 & 0 & -\dot{\alpha}\left(\overrightarrow{O_{t} D_{1}} \cdot \boldsymbol{y}\right) \\
0 & 1 & 0 & \dot{\alpha}\left(\overrightarrow{O_{t} D_{1}} \cdot \boldsymbol{x}\right) \\
0 & 0 & 1 & 0 \\
0 & 0 & 0 & 0
\end{array}\right], } \\
& \boldsymbol{T}_{2}=\left[\begin{array}{cccc}
1 & 0 & 0 & -\dot{\alpha}\left(\overrightarrow{O_{t} D_{2}} \cdot \boldsymbol{y}\right) \\
0 & 1 & 0 & \dot{\alpha}\left(\overrightarrow{O_{t} D_{2}} \cdot \boldsymbol{x}\right) \\
0 & 0 & 1 & 0 \\
0 & 0 & 0 & 0
\end{array}\right],
\end{aligned}
$$

and $\boldsymbol{x}, \boldsymbol{y}$ represent the unit vectors of $x$ and $y$ axes in $\Sigma_{b}$, respectively. Assuming that the mass of bars of parallelogram is neglected, the dynamic equation can be written as:

$$
\begin{aligned}
\boldsymbol{\tau}= & \left(\boldsymbol{I}_{v a}+\boldsymbol{I}_{m}\right) \ddot{\boldsymbol{\theta}}+\boldsymbol{J}^{T} \boldsymbol{M}_{b c}\left(\ddot{\boldsymbol{p}}-\boldsymbol{g}-\boldsymbol{F}_{e x t}\right) \\
& +\left(\boldsymbol{T}_{1} \boldsymbol{J}\right)^{T} \boldsymbol{M}_{b l}\left(\ddot{\boldsymbol{p}}_{c 1}-\boldsymbol{g}\right)+\left(\boldsymbol{T}_{2} \boldsymbol{J}\right)^{T} \boldsymbol{M}_{b l}\left(\ddot{\boldsymbol{p}}_{c 2}-\boldsymbol{g}\right)
\end{aligned}
$$

$\boldsymbol{\tau}$ and $\boldsymbol{F}_{\text {ext }}$ are the actuator's torque and the external force acting on the traveling plate, respectively. $\boldsymbol{I}_{m}$, $\boldsymbol{I}_{v a}, \boldsymbol{M}_{b c}$ and $\boldsymbol{M}_{b l}$ are the inertia matrix of an actuator, the inertia matrix of virtual arm, the mass matrix of the central bar and the mass matrix of lateral bar, respectively. They can be written as:

$$
\begin{aligned}
\boldsymbol{I}_{m} & =\operatorname{diag}\left[\begin{array}{llll}
i_{m o t} & i_{m o t} & i_{m o t} & i_{m o t}
\end{array}\right], \\
\boldsymbol{M}_{b c} & =\operatorname{diag}\left[\begin{array}{llll}
m_{b c} & m_{b c} & m_{b c} & i_{b c}
\end{array}\right], \\
\boldsymbol{M}_{b l} & =\operatorname{diag}\left[\begin{array}{llll}
m_{b l} & m_{b l} & m_{b l} & 0
\end{array}\right]
\end{aligned}
$$

where $\operatorname{diag}[\bullet]$ represent a diagonal matrix, and the diagonal elements of respective diagonal matrices. $i_{m o t}$, $i_{b c}, m_{b c}$ and $m_{b l}$ represent the inertia of motor, the inertia of the central bar, the mass of the central bar and the mass of the lateral bar, respectively.

Then, the dynamic equation can be rewritten as:

$$
\boldsymbol{\tau}=\boldsymbol{I}(\boldsymbol{\theta}) \ddot{\boldsymbol{\theta}}+\boldsymbol{h}(\dot{\boldsymbol{\theta}}, \boldsymbol{\theta})
$$

where,

$$
\begin{aligned}
\boldsymbol{I}(\boldsymbol{\theta})= & \left(\boldsymbol{I}_{v a}+\boldsymbol{J}_{m}\right)+\boldsymbol{J}^{T} \boldsymbol{M}_{b c} \boldsymbol{J}+\left(\boldsymbol{T}_{1} \boldsymbol{J}\right)^{T} \boldsymbol{M}_{b l}\left(\boldsymbol{T}_{1} \boldsymbol{J}\right) \\
& \left.+\boldsymbol{T}_{2} \boldsymbol{J}\right)^{T} \boldsymbol{M}_{b l}\left(\boldsymbol{T}_{2} \boldsymbol{J}\right) \\
\boldsymbol{h}(\dot{\boldsymbol{\theta}}, \boldsymbol{\theta})= & \left\{\boldsymbol{J}^{T} \boldsymbol{M}_{b c} \dot{\boldsymbol{J}}+\left(\boldsymbol{T}_{1} \boldsymbol{J}\right)^{T} \boldsymbol{M}_{b l}\left(\boldsymbol{T}_{1} \dot{\boldsymbol{J}}+\dot{\boldsymbol{T}}_{1} \boldsymbol{J}\right)\right. \\
& \left.+\left(\boldsymbol{T}_{2} \boldsymbol{J}\right)^{T} \boldsymbol{M}_{b l}\left(\boldsymbol{T}_{2} \dot{\boldsymbol{J}}+\dot{\boldsymbol{T}}_{2} \boldsymbol{J}\right)\right\} \dot{\boldsymbol{\theta}} \\
& -\left\{\left(\boldsymbol{T}_{1} \boldsymbol{J}\right)^{T}+\left(\boldsymbol{T}_{2} \boldsymbol{J}\right)^{T}\right\} \boldsymbol{M}_{b l} \boldsymbol{g}+\boldsymbol{J}^{T} \boldsymbol{M}_{b c} \boldsymbol{F}_{e x t}
\end{aligned}
$$

\section{Control of the $\mathrm{H} 4$}

A precise model of the $\mathrm{H} 4$ robot is constructed by $\mathrm{ADAMS}^{\mathrm{TM}}$. It is a commercial software package 


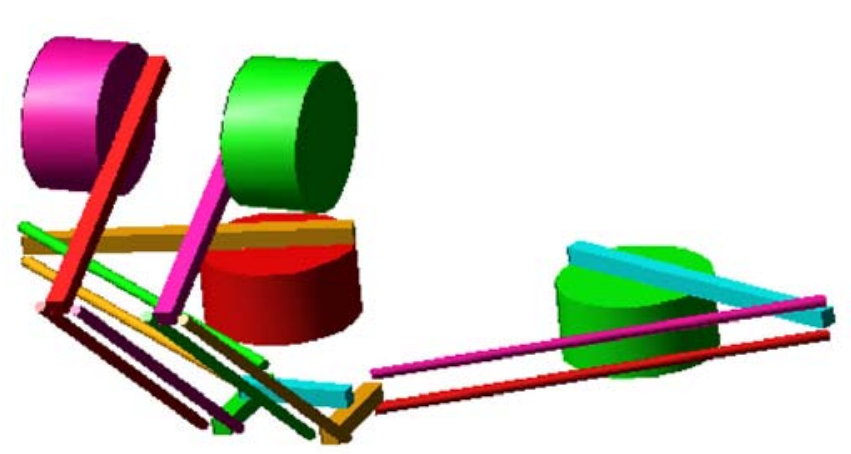

(a) A Conceptual design

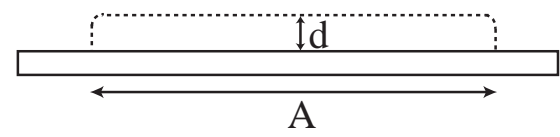

(b) The Adept motion

Figure 7: Conceptual design and Adept motion

for dynamic analysis of mechanical systems produced by Mechanical Dynamics, Inc. The conceptual model used in the simulation is shown in Figure 7 (a).

\subsection{The Adept motion}

The Adept motion is chosen here as a benchmark test to evaluate the motion performance of the $\mathrm{H} 4$. Figure 7 (b) illustrates an example of the Adept motion. The dotted curve in the figure represents the trajectory. No restriction is placed on the curving of corners. Figure 8 illustrate the control block diagrams used in this simulation. This simulation targets the attainment of the quickest motion. The start, stop points and the height are $(X, Z)=(-0.15,-0.52)$ $[\mathrm{m}],(0.15,-0.52)[\mathrm{m}]$ and $\mathrm{d}=0.025[\mathrm{~m}]$, respectively.

Furthermore, a wait was inserted on both ends of the trajectory in order to secure a static period assuming that the robot performs a pick-and-place operation. The length of the wait was set to $0.02[\mathrm{~s}]$. In the simulation, the control gains, $K_{p}, K_{d}$ and $K_{v}$ were set to $100\left[\mathrm{~s}^{-1}\right], 2.5$ and $11[\mathrm{Nm} /(\mathrm{rad} / \mathrm{s})]$, respectively.

\subsection{Control schemes}

The motor drivers of the $\mathrm{H} 4$ provide the hardware velocity servo, therefore the torques cannot be directly commanded to the motor drivers. Therefore, the torque command has to be converted into the velocity command as follows. The P-velocity control of

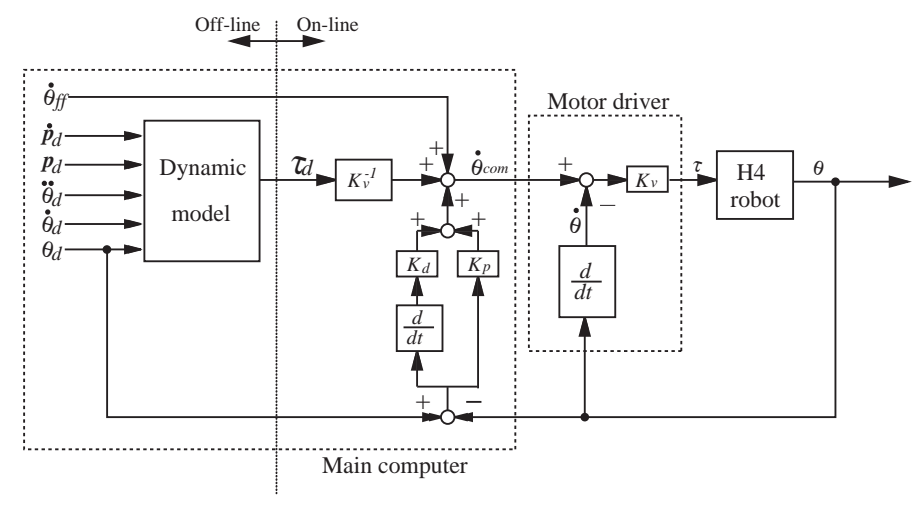

Figure 8: Dynamic control scheme

the motor driver is assumed to be

$$
\boldsymbol{\tau}=K_{v}\left(\dot{\boldsymbol{\theta}}_{c o m}-\dot{\boldsymbol{\theta}}\right)
$$

where $\boldsymbol{\tau}$ denotes the motor torque vector, $\dot{\boldsymbol{\theta}}_{\text {com }}$ is the velocity command vector and $\boldsymbol{\theta}$ is the current motor angular velocity vector. To compare the performance characteristic such as trajectory and control, the following control methods are applied.

\subsubsection{PD control}

In PD control, the velocity command vector $\dot{\boldsymbol{\theta}}_{\text {com }}$ is given by,

$$
\dot{\boldsymbol{\theta}}_{c o m}=K_{p}\left(\boldsymbol{\theta}_{d}-\boldsymbol{\theta}\right)+K_{d}\left(\dot{\boldsymbol{\theta}}_{d}-\dot{\boldsymbol{\theta}}\right),
$$

where, $\boldsymbol{\theta}_{d}$ denotes the desired motor angle vector, $\boldsymbol{\theta}$ is the current motor angle vector.

\subsubsection{PD with velocity feed-forward control}

In PD with velocity feed-forward control, the velocity command vector $\dot{\boldsymbol{\theta}}_{\text {com }}$ is calculated as:

$$
\dot{\boldsymbol{\theta}}_{c o m}=\dot{\boldsymbol{\theta}}_{f f}+K_{p}\left(\boldsymbol{\theta}_{d}-\boldsymbol{\theta}\right)+K_{d}\left(\dot{\boldsymbol{\theta}}_{d}-\dot{\boldsymbol{\theta}}\right),
$$

where, $\dot{\boldsymbol{\theta}}_{f f}$ is a feed-forward term to compensate the sampling time delay, and it is given by:

$$
\dot{\boldsymbol{\theta}}_{f f}(t)=\dot{\boldsymbol{\theta}}_{d}(t+\Delta T)
$$

\subsubsection{Dynamic control}

In the dynamic control, the velocity command vector $\dot{\boldsymbol{\theta}}_{\text {com }}$ is given by,

$$
\dot{\boldsymbol{\theta}}_{c o m}=K_{v}^{-1} \boldsymbol{\tau}_{d}+\dot{\boldsymbol{\theta}}_{f f}+K_{p}\left(\boldsymbol{\theta}_{d}-\boldsymbol{\theta}\right)+K_{d}\left(\dot{\boldsymbol{\theta}}_{d}-\dot{\boldsymbol{\theta}}\right)
$$




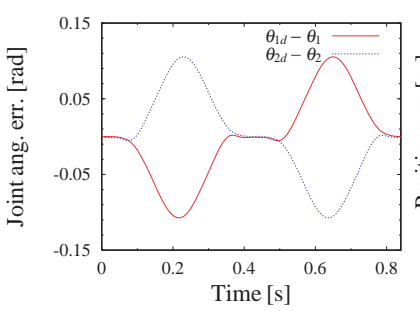

(a) Motor angle

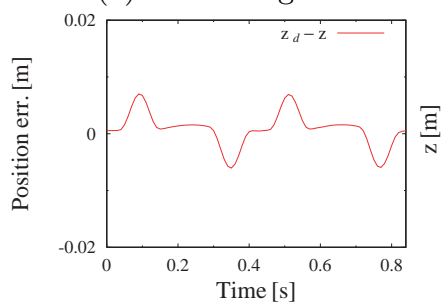

(c) Trajectory of $\mathrm{z}$

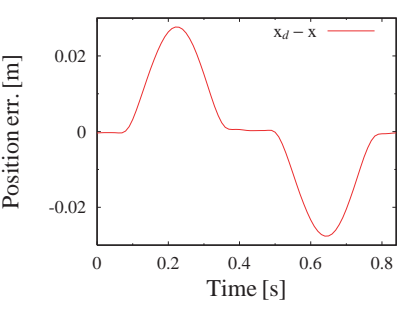

(b) Trajectory of $\mathrm{x}$

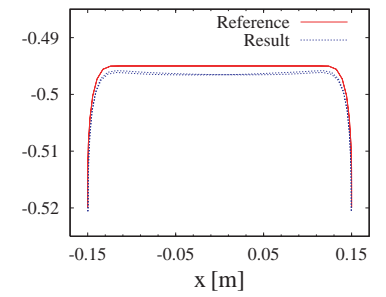

(d) Trajectory of $x-z$
Figure 9: PD control

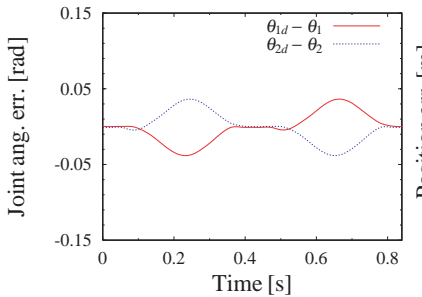

(a) Motor angle

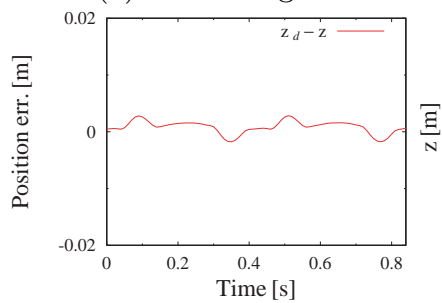

(c) Trajectory of $\mathrm{z}$

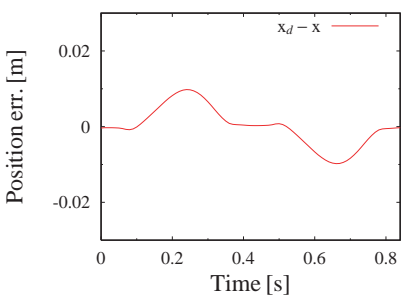

(b) Trajectory of $\mathrm{x}$

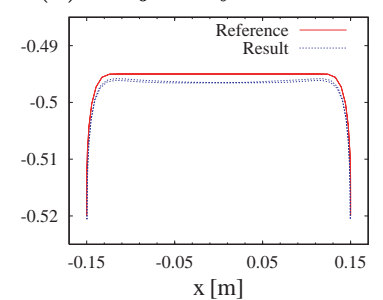

(d) Trajectory of $\mathrm{x}-\mathrm{z}$
Figure 10: PD control with velocity feed-forward

where $\boldsymbol{\tau}_{d}$ denotes the torque vector calculated from the equation of motion using the target trajectory. The time of 1 cycle was set to 0.84 [s] in the all above simulation. To compare the control result, the time of 1 cycle was set to $0.49[\mathrm{~s}]$ and the simulation was done using dynamic control.

\subsection{Simulation results}

The simulation result for PD control, PD with velocity feed-forward control, dynamic control and dynamic control with the shorten time of 1 cycle $(0.49[\mathrm{~s}])$ are shown in Figure 9, Figure 10, Figure 11, and Figure 12 , respectively. In each figure, (a), (b) $\sim(c)$, and

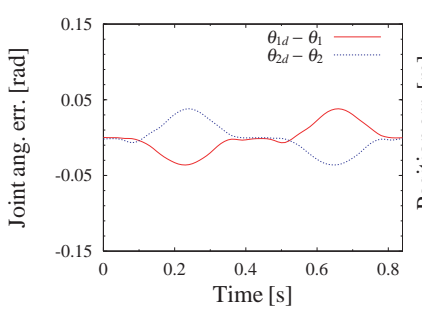

(a) Motor angle

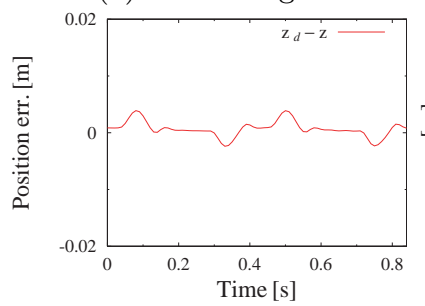

(c) Trajectory of $\mathrm{z}$

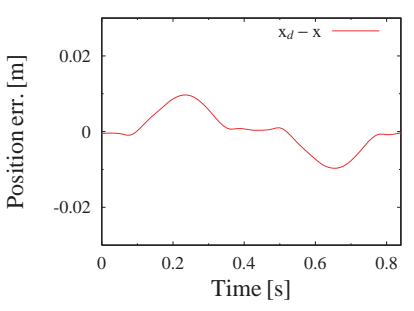

(b) Trajectory of $\mathrm{x}$

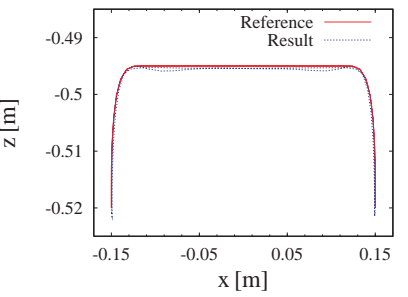

(d) Trajectory of $x-z$
Figure 11: Dynamic control

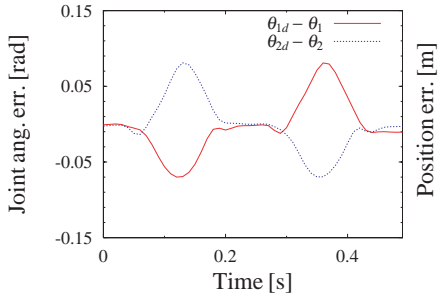

(a) Motor angle

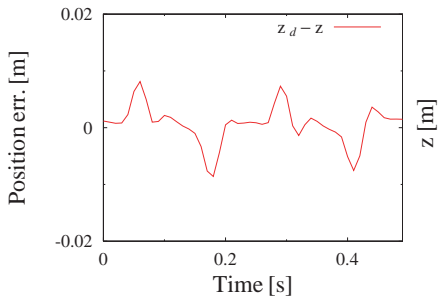

(c) Trajectory of $\mathrm{z}$

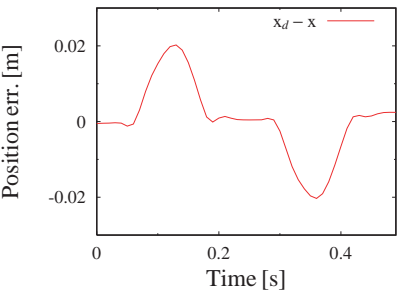

(b) Trajectory of $\mathrm{x}$

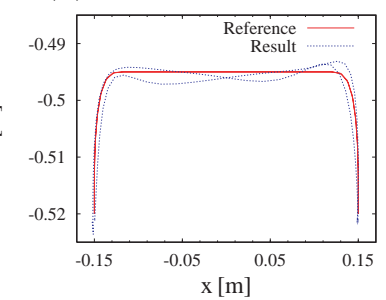

(d) Trajectory of $x-z$
Figure 12: Dynamic control (cycle time $0.49[\mathrm{~s}]$ )

(d) represent the motor angle errors of the $\theta_{1}$ and $\theta_{2}$, the travelling plate trajectory errors of $\mathrm{z}$, and the desired traveling plate trajectory with the current traveling plate trajectory, respectively.

In the result of PD control, there is a considerable delay in position (Figure 9) but in the result of PD with the velocity feed-forward control, the trajectory-tracking accuracy is improved considerably (Figure 10). In the result of dynamic control, the delay in position cannot be seen (Figure 11). In addition, when the time of 1 cycle is shortened, the trajectorytracking accuracy is not improved even if a dynamic control is applied (Figure 12). Figure 13 show the motor torques at each simulation. When the 1 cycle time 


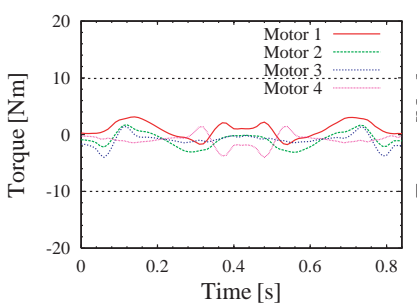

(a) 1 Cycle $(0.84[\mathrm{~s}])$

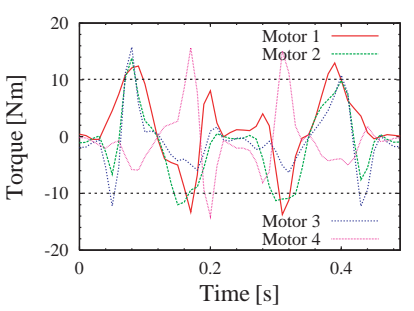

(b) 1 Cycle $(0.49[\mathrm{~s}])$
Figure 13: Motor torque

is set to $0.84[\mathrm{~s}]$, the motors torque are in the range of $\pm 5[\mathrm{Nm}]$. But when the 1 cycle time is set to $0.49[\mathrm{~s}]$, the motors torque exceed the rating torque. Therefore, if this motion was given to the real model, the motor torque would be saturated. Consequently, it is considered that the trajectory-tracking accuracy will not be improved and the overshoot problem will occur in the real $\mathrm{H} 4$.

\section{Conclusion}

In this paper, we presented the dynamic simulation of $\mathrm{H} 4$ using $\mathrm{ADAMS}^{\mathrm{TM}}$ in order to show that the dynamic control can improve the trajectory-tracking accuracy. This simulation demonstrated that the H4 is promising as a high-speed robot mechanism. From the simulation result, it is thought that the trajectorytracking accuracy of the prototype of $\mathrm{H} 4$ can be improved using the dynamic control if the motor torque is less than the maximum torque. The results also show that the simplified dynamic model is effective in order to improve the accuracy of trajectory control. Moreover, the results show at the same time that the PD control with velocity feed-forward also improves the trajectory-tacking accuracy considerably.

\section{References}

[1] V. E. Gough: "Contribution to Discussion to Papers on Research in Automobile Stability and Control and in Tire Performance," Proc. Auto. Div. Inst. Mech. Engrs, 1956-1957.

[2] D. Stewart: "A Platform with Six Degrees of Freedom," Proc. of the Institution of Mechanical Engineers, vol. 180, pt. I, no. 15, pp. 371-386, 1965-1966.

[3] M. Minsky: "Manipulator Design Vignettes," MIT AL Memo, No. 267, MIT AI Labo, 1972.

[4] H. McCallion and D. T. Phan: "The Analysis of a Six-Degree-of Freedom Work Station for Mechanized Assembly," Proc. of the 5th World Congress on Theory of Machines and Mechanisms, pp. 611-616, 1979.
[5] K. H. Hunt: "Structural kinematics of in-parallelactuated robot-arms," Trans. ASME, J. of Mechanisms, Transmissions, and Automation in Design, vol. 105, pp. 705-712, 1983.

[6] T. Kokkinis and R. Stoughton: "Optimal parallel actuation linkage for 3 DOF elbow manipulators," Proc. of the 1988 ASME Design Technology Conferences, DE-vol. 15, no. 3, pp. 465-472, 1988.

[7] R. Clavel: "DELTA, a fast robot with parallel geometry," in 18th Int. Symp. on Industrial Robot, pp. 91-100, Lausanne, Avril 1988

[8] T. Arai, R. Stoughton, K. Homma, H. Adachi, T. Nakamura: "Development of a Parallel Link Manipulator," Proc. of the 5th Int. Conf. Advanced Robotics, vol. 1, Pisa, June 19-22, pp. 839-844, 1991

[9] F. Pierrot, M. Uchiyama, P. Dauchez and A. Fournier: "A New Design of a 6-DOF Parallel Robot," J. of Robotics and Mechatronics, vol. 2, no. 4, pp. 308-315, 1990.

[10] M. Uchiyama, K. I. Iimura, F. Pierrot, P. Dauchez, K. Unno and O. Toyama: "A New Design of a Very Fast 6-DOF Parallel Robot," Proc. of the 23rd International Symposium on Industrial Robots, pp. 771-776, 1992.

[11] M. Uchiyama, K. Masukawa and T. Sadotomo: "Experiment on Dynamic Control of a HEXA-Type Parallel Robot," Proc. of the 1st World Automation Congress (WAC '94), vol. 2, pp. 281-286, 1994.

[12] F. Pierrot and O. Company: "H4: a new family of 4-dof parallel robots," Proc. of the IEEE/ASME Int. Conf. on Advanced Intelligent Mechatronics, Atlanta, Georgia, USA, September, pp. 508-513, 1999.

[13] O. Company and F. Pierrot: "A new 3T-1R parallel robot," Proc. of the 9th Int. Conf. on Advanced Robotics, Tokyo, Japan, October 25-27, pp. 557-562, 1999 ,

[14] F. Pierrot, F. Marquet, O. Company and T. Gil: "H4 parallel robot: modeling and preliminary experiment," Proc. of the IEEE Int. Conf. On Robotics and Automation, Seoul, Korea, May 2001.

[15] D. Kim, K. ABE, T. Shitashimizu, D. Sato and M. Uchiyama: "Design of a Ball Joint and Rod with Large Swing angle for a Parallel Robot in Which Epoxy-Type Bond is Used," The Japan Society of Mechanical Engineers, vol. 66, no. 676, pp. 3666-3672, 2002. (in Japaness) 